\title{
ETHICAL DIMENSIONS OF SOCIAL MARKETING DOES TRYING TO DO GOOD EQUATE TO DOING NO HARM?
}

\author{
Lynne Eagle, University of the West of England, U.K. \\ Sara Bird, University of the West of England, U.K. \\ Fiona Spotswood, University of the West of England, U.K. \\ Alan Tapp, University of the West of England, U.K.
}

\begin{abstract}
Social marketing aims to improve the health and wellbeing of society; however the development and implementation of interventions may have ethical repercussions for both intended and incidental targets, and in general ethical terms. To date there is little systematic analysis in the literature of these issues or possible solutions. There is a lack of unambiguous ethical frameworks to guide social marketers, with different outcomes possible under intention-focused (deontological) reasoning versus consequence-focused (teleological) reasoning. While ethical checklists and codes of ethics have been proposed for the sector, significant questions relating to administration and enforcement remain unresolved. This article reviews these issues and suggests routes for developing such guidelines and codes, and future research.
\end{abstract}

\section{INTRODUCTION}

Since the 1950s, there have been calls for the appropriation of commercial marketing techniques to the achievement of social good through behaviour change, a discipline termed 'social marketing' since Kotler and Zaltman's seminal 1971 paper. A more recent definition describes social marketing as "the adaptation of commercial marketing technologies to the analysis, planning, execution and evaluation of programs designed to influence the behaviour of target audiences in order to improve their physical and mental wellbeing and/or that of the society of which they are a part" (Andreasen, 1993: 1). The last decade has seen a rapid escalation in debate about the theory and practice of social marketing as it is adopted across wider geographic and behavioural spheres, such as healthcare, environment and wider social good. The number of practitioners has also ballooned, prompting calls for industry standards of practice, particularly with respect to ethical practices.

Since its inception, social marketing has been under close ethical scrutiny and there is no question that consistently high ethical standards should be expected of practitioners given the potential impact of interventions on individuals and society. Sources of concern lay in determining suitable behavioural goals in pursuit of the intrinsically ethical aim of achieving 'social good'; in who has the right to make such decisions; and in implementation and how it impinges upon both intended targets and bystanders. Here we seek to identify some of the most common sources of ethical concern in social marketing and to review current procedures for supporting and guiding practitioners. We go on to suggest avenues for development of ethical guidelines and codes of practice, and areas for future research.

\section{ETHICAL ISSUES}

One broad question is how individual freedoms of choice and individual rights are balanced against the needs of society as a whole. The ethics of using social marketing to change behaviour in one group at the behest of another are debatable. A related issue is who defines desired behaviour and decides what 'social good' is. Guttman and Salmon (2004) also ask "who has the mandate to represent large and diverse populations for the purpose of informed consent, and how can this be implemented?": the criteria for such choices are not clear.

The choice of target group poses further ethical questions. If social marketers simply "select target markets they can best affect and satisfy" (Kotler, Roberto and Lee 2002: 7), segments of the population may be excluded because they are difficult or comparatively costly to reach (Brenkert 2002). The temptation to target 'low hanging fruit' (such as middle class smokers) may bring more rapid and cost-effective success but widen health inequalities as we fail to support the most entrenched groups. If the latter are targeted, but intervention costs are significantly more than those aimed at lower priority groups, is it ethical to focus resources on one 'hard to reach' group at the expense of others? Targeting children or adolescents, when long-term behaviours such as smoking are becoming habitualised, raises issues of consent and coercion. Young people should not feel coerced into participation in social marketing interventions simply to please "parents or other authority figures" (Moolchan and Mermelstein 2002).

The harm to both intentional and untargeted (incidental) groups that may arise as a consequence of social marketing interventions should be considered in the development of any intervention. A wide range of unintended effects of health communication campaigns 
have been reported (summarised in Table 1). For instance, safe sex messages may offend some cultural or religious groups who may not be directly targeted but still witness interventions (Brenkert 2002).

Many of the unintended effects of health communication campaigns could be attributable to fear appeals, i.e. dissonance, discomfort and distress, boomerang effects, epidemics of apprehension and desensitisation (Cho and Salmon 2007; Witte and Allen 2000). Early AIDS campaigns used strong fear appeals which aroused anxiety and fear amongst low-risk groups (Murphy and Bloom 1992), while potentially stigmatising, desensitising and alienating high-risk groups. Further, those who respond to fear-based campaigns tend to be better educated and more affluent than average (Hastings, Stead and Webb, 2004). Caution is required for fear appeals for less educated segments and there is a need for research into the attitudes, information needs and message framing preferences of these groups. There are also pragmatic reasons for caution in using fear appeals: despite laboratory studies which establish short-term effectiveness, realworld effects do not show the same results (Hastings et al. 2004). Additionally, strong fear appeals are unethical if target populations do not believe they can undertake the recommended behaviour or that it will be effective in reducing the perceived threat (Snipes et al. 1999).

These ethical challenges are highly subjective and will be viewed differently around the world, so before assessing how to address them it is worth considering the various ethical frameworks that could be used.

\section{ETHICAL FRAMEWORKS}

The guidelines and codes outlined below, and the issues suggested above, arise from the often implicit ethical frameworks of Greek and other philosophies. There are a number of frameworks available, but there is no consistency in the literature as to which might apply in specific circumstances. The frameworks most commonly cited focus either on intentions (deontology, from the Greek word for 'duty') or consequences (teleology, from the Greek word for 'ends'; also referred to as consequentialism), with the latter being broken down further into utilitarianism and egoism (Andreasen 2001; Ferrell and Fraedrich 1994). Thus a social marketing intervention that was driven by good intentions without potential negative consequences being considered is acceptable under deontological reasoning but not under teleological reasoning. A relativist view would suggest that no universal set of ethics can apply across all sectors of society due to the increasing diversity of society, with different perspectives held even within cultures; therefore each group's ethical perspective should be held to be equally valid. Additionally, social contract theory suggests that there is an implicit contract between the state/government and individuals within society (Dunfee et al. 1999). This is reflected in documents such as the UN Charter which makes reference to basic assumptions about the right of all citizens to health (Easley et al. 2001).

The role of culture in establishing ethical standards is largely ignored within the marketing literature (Pires and Stanton 2002). For example, Saeed and Mukhtar (2001) suggest that use of fear appeals is contrary to Islamic beliefs, therefore can interventions based on fear appeals ever be acceptable? How should social marketers balance respect for minority cultural norms with the desire to challenge them in the interests of improving health and well-being (Guttman and Salmon 2004)?

A further problem is the lack of clear interpretation of the frameworks. For example, using the Ferrell and Fraedrich (1994) interpretation, the 2007 UK Department of Health 'fishhook' intervention, which featured smokers being dragged to purchase cigarettes by fishhooks through their faces, would be acceptable under deontological reasoning, as the intention was to help smokers to quit smoking. Using the same reasoning, others would argue that it is unacceptable to knowingly cause anxiety (Hastings et al. 2004; Duke et al. 1993). Their argument is that, even though the intention was to help a specific segment of society, the methods used caused harm (anxiety) for others, thereby violating the utilitarian principle of producing the greatest good for the greatest number.

Despite the importance of the topic, much of the material promoting the potential benefits of social marketing is devoid of any significant consideration of ethical issues. Even edited texts focussing specifically on ethics in social marketing (e.g. Andreasen 2001) do not provide consistent frameworks across the discipline.

\section{EXISTING ETHICAL GUIDELINES AND CODES OF PRACTICE}

There is a clear need for systems or structures to help prevent or resolve ethical issues in social marketing. Around the world, codes of practice have been developed to govern commercial marketing communications, often through co-operation between advertisers, advertising agencies and the media. They often provide advisory services, interpreting relevant statutes and industry codes and applying them to scripts of proposed advertisements and vetting completed advertisements prior to screening. These regulations do not state explicit ethical principles, providing only general guidelines regarding areas such as decency and circumstances under which fear and distress might be considered acceptable, yet recent rulings suggests that a de facto framework exists. The focus is generally on marketing communications only and there is no equivalent structure for wider social marketing interventions beyond mass media. 
The American Marketing Association (AMA 2007) provides a broader code of ethics for its members:

“ 1. Marketers must do no harm.

2. Marketers must foster trust in the marketing system (not mislead), good faith and fair dealing.

3. Marketers must embrace, communicate and practice fundamental ethical values that will improve consumer confidence in

the integrity of the marketing exchange system. These basic values are intentionally aspirational and include honesty, responsibility, fairness, respect, openness and citizenship".

The broad nature of this code provides little explicit guidance for social marketers seeking support.

The fragmentation of the marketing industry also presents a barrier; while many sector organisations have codes there are no overarching industry mechanisms within individual countries, let alone cross-border initiatives. The European Association of Communication Agencies (EACA, 2007) approaches this, however such codes are little more than statements of good intent and lack specific guidance. For example, the EACA's Code of Ethics states that "[w]e accept that our understanding of the "average consumer" might not always be the standard, acknowledging that there are groups who are vulnerable, for example, and that we should adopt a sensitive approach to judging how advertising will be understood and acted upon by society in general".

A doctor, accountant or lawyer could lose the right to practice if found guilty by their peers of a significant transgression of professional ethics (Cruess and Cruess 1997), however marketers are not subject to the same level of regulation and lack the ability to enforce such codes (Hunt and Vitell 2006). Marketers need not be licensed and membership of sector organisations is voluntary. If a marketer is found guilty of transgressing the implicit or explicit standard of behaviour for any sector organisation to which they belong, they may be excluded from that organisation, but this does not prevent them from continuing in employment in the sector. There are less direct sanctions available to the industry overall in many countries. For example self-regulatory bodies can withdraw or amend marketing communications in breach of codes, and industry regulators can request media to deny advertising space or discounts to non-compliant marketers. In many countries, legal support to enforce discontinuation of unacceptable material is available, though such regulation only focuses on marketing communications and is of limited value for broader social marketing interventions.

The healthcare sector has many commonalities with social marketing and four key principles from medicine are more specific than the 'good intentions' for the AMA above and may be of relevance to social marketing, i.e.:

“ 1. Respect for autonomy of individuals or communities, requirement for consultation and agreement (i.e. effective two-way communication) and absence of deceit

2. Beneficence, i.e. provision of net benefit to target group or patient

3. Obligation to ensure no harm is caused by actions

4. Justice in terms of fairness in distributing resources, respecting of rights and for morally accepted law" (Gillon 1994).

We would add the necessity of recognising the extent, and boundaries, of our expertise as marketers; few of us are formally qualified in medical or related health fields in which much social marketing activity occurs, such as smoking cessation and exercise promotion programmes. There is, however, a recognised role for communication expertise in improving health and other social issues, and as such, guidance or codes of ethics can only improve our practice.

\section{DEVELOPING SOCIAL MARKETING GUIDELINES AND CODES OF ETHICS}

Two broad approaches may be useful in guiding practitioners and sensitising them to potential issues. Firstly, guidelines for social marketers would help define potential issues and suggest how to mitigate their consequences. Such an ethical checklist for social marketing is proposed by Donovan and Henley (2003):

- Ensure that the intervention will not cause physical or psychological harm

- Does the intervention give assistance where it is needed?

- Does the intervention allow those who need help the freedom to exercise their entitlements?

- Are all parties treated equally and fairly?

- Will the choices made produce the greatest good for the greatest number of people?

- Is the autonomy of the target audience recognised?

More formal codes have also been proposed for social marketing, such as Rothschild's (2001) code of ethics for social marketing:

- Do more good than harm

- Favour free choice

- Evaluate marketing within a broad context of behaviour management (giving consideration to alternatives of education and law)

- Select tactics that are effective and efficient 
- Select marketing tactics that fit marketing philosophy (that is meeting the needs of consumers rather than the self-interest of the organisation)

- Evaluate the ethicality of a policy before agreeing to develop a strategy

However, codes are not a panacea as they are often broad statements of intent and cannot cover every situation that will arise or provide guidance on how specific issues can be resolved (Wright 1993). Neither of the above addresses the impact of interventions on intentional targets versus incidental exposure, nor the ethicality of the chosen solution to perceived problems, or the mandate for developing and implementing interventions per se. Sectors such as marketing lack the enforcement mechanisms of more regulated professions, so could codes of ethics ever be more than statements of desired best practice (Lere and Gaumnitz 2007)? Such voluntary codes also require input from all stakeholders, to ensure effectiveness (Rust et al. 2006). Social marketing activity also occurs across a range of sectors, including health, environmental planning and marketing; developing codes that can be applied across all sectors, some with existing codes, is problematic. It is therefore evident that considerably more work needs to be done to develop a viable code of ethics and appropriate management and enforcement mechanisms for all social marketers.

\section{CONCLUSIONS}

While it is a positive step that ethical issues within social marketing are being discussed, much work remains to be done in drafting codes and developing administration and enforcement mechanisms. Underpinning frameworks need to be agreed and input is required from all stakeholders. Codes can never be exhaustive and guidelines and support are required for practitioners facing ethical dilemmas. There is also a need to raise awareness and offer training to highlight the issues that should be considered when developing social marketing interventions. Future research needs to assess what these issues are and how codes of ethics can best be presented and enforced. These challenges are significant, but the rapid development of social marketing requires such guidelines and codes to protect publics, both targeted and incidental, and the discipline as a whole.

\section{TABLES}

Table 1: Unintended Effects of Health Communication Campaigns (Adapted from Cho and Salmon 2007: 300)

\begin{tabular}{|l|l|}
\hline Effect & Definition \\
\hline Obfuscation & Confusion and misunderstanding of health risk and risk prevention methods \\
\hline Dissonance & Psychological distress caused by incongruence between recommended health states and actual states \\
\hline Boomerang & Reaction by an audience that is the opposite to the intended response of the persuasion message \\
\hline Epidemic of apprehension & Unnecessarily high concern produced by pervasive risk messages over the long term \\
\hline Desensitisation & Repeated, long-term exposure to messages about a health risk may render the public apathetic \\
\hline Culpability & Locating the causes of public health problems in the individual rather than social conditions \\
\hline Opportunity cost & Choice of communication campaigns/health issues removes alternative options \\
\hline Social reproduction & When campaigns reinforce existing social distributions of knowledge, attitudes and behaviours \\
\hline Social norming & Social cohesion/control accompanying marginalisation of unhealthy minorities \\
\hline Enabling & Campaigns inadvertently promote power of individuals/institutions and promote industry \\
\hline System activation & Campaigns influence unintended segments, whose actions mediate effects on intended audience \\
\hline
\end{tabular}

\section{REFERENCES}

American Marketing Association (AMA). 2007. American Marketing Association Code of Ethics: Ethical Norms and Values for Marketers. Retrieved from http:/www.marketingpower.com/content21013.php\#

Andreasen, Alan R. (Ed.). 2001. Ethics in Social Marketing. Washington DC: Georgetown University Press

Andreasen, Alan R. 2002. "Marketing Social Marketing in the Social Change Marketplace.” Journal of Public Policy and Marketing 21(1): 3-13

Brenkert, George G. 2002. "Ethical Challenges of Social Marketing.” Journal of Public Policy and Marketing 21(1): 14-36

Cho, Hyunyi and Charles T. Salmon. 2007. "Unintended Effects of Health Communication Campaigns." Journal of Communication 57(2): 293-317 
Cruess, Sylvia and Richard L. Cruess. 1997. “Professionalism Must Be Taught”. British Medical Journal 7123(315): 1674-1677

Donovan, Robert and Nadine Henley. 2003. Social Marketing Principles and Practice. Melbourne, Australia: IP Communications

Duke, Charles R.., Gregory M. Pickett, Les Carlson and Stephen J. Grove. 1993. "A Method for Evaluating the Ethics of Fear Appeals." Journal of Public Policy and Marketing 12(1): 120-129

Dunfee, Thomas W., N. Craig Smith and William T. Ross Jr. 1999. "Social Contracts and Marketing Ethics." Journal of Marketing 63(3): $14-32$

Easley, Cheryl E., Stephen P. Marks, Docteur D'Etat and Russell B. Morgan Jr. 2001. "The Challenge and Place of International Human Rights in Public Health”. American Journal of Public Health 91(12): 1922-1925

European Association of Communications Agencies (EACA). 2007. Code of Ethics. Retrieved from http://www.eaca.be/documentation/results.asp?type=1andopen=4and\#4

Ferrell, O. C., and John B. Fraedrich. 1994. Business Ethics: Ethical Decision Making and Cases (2nd ed.). Boston: Houghton Mifflin

Gillon, Raanan. 1994. “Medical Ethics: Four Principles Plus Attention to Scope.” British Medical Journal 309(6948): 184

Guttman, Nurit and Charles T. Salmon. 2004. "Guilt, Fear, Stigma and Knowledge Gaps: Ethical Issues in Public Health Communication Interventions". Bioethics 18(6): 53 -552

Hastings, Gerard, Martine Stead and John Webb. 2004. "Fear Appeals in Social Marketing Strategic and Ethical Reasons for Concern." Psychology and Marketing 21(11): 961-986

Hunt, Shelby D., and Scott J. Vitell. 2006. "The General Theory of Marketing Ethics: A Revision and Three Questions.” Journal of Macromarketing 26(2): 143-153

Kotler, Philip, Ned Roberto and Nancy Lee. 2002. Social Marketing: Improving the Quality of Life. Thousand Oaks, CA: Sage Publications

Kotler, Philip, and Gerald Zaltman. 1971. “Social Marketing: An Approach to Planned Social Change.” Journal of Marketing 35(3): 3-12

Lere, John C., and Bruce R. Gaumnitz. 2007. "Changing Behavior by Improving Codes of Ethics.” American Journal of Business 22(2): $7-17$

Moolchan, Eric T., and Robin Mermelstein. 2002. "Research on Tobacco Use Among Teenagers: Ethical Challenges." Journal of Adolescent Health 30(6): 409 - 417

Murphy, Patrick E., and Paul N. Bloom. 1992. "Ethical Issues in Social Marketing”. In Marketing the Public Sector Promoting the Causes of Public and Nonprofit Agencies: 68-78: Transaction Publishers

Pires, Guilherme D. and John Stanton. 2002. "Ethnic Marketing Ethics.” Journal of Business Ethics 36(1/2): 111-118

Rothschild, Michael L. 2001. "Ethical Considerations in the Use of Marketing for the Management of Public Health and Social Issues." In Alan R. Andreasen (Ed.). Ethics in Social Marketing (pp. 17-38). Washington DC: Georgetown University Press

Rust, Roland T., and Tuck S. Chung. 2006. “Marketing Models of Service and Relationships.” Marketing Science 25(6): 560-580

Saeed, Mohammed, Zafar U. Ahmed, and Syeda-Masooda Mukhtar. 2001. "International Marketing Ethics from an Islamic Perspective: A Value-Maximization Approach" Journal of Business Ethics 32(2): 127-142

Snipes, Robin L., Michael S. LaTour and Sara J. Bliss. 1999. "A Model of the Effects of Self-efficacy on the Perceived Ethicality and Performance of Fear Appeals in Advertising.” Journal of Business Ethics 19(3): 273-285 
Witte, Kim and Mike Allen. 2000. “A Meta-Analysis of Fear Appeals: Implications for Effective Public Health Campaigns". Health Education and Behavior 27(5): 591-615

Wright, Donald K. 1993. “Enforcement Dilemma: Voluntary Nature of Public Relations Codes.” Public Relations Review 19(1): 13-20 